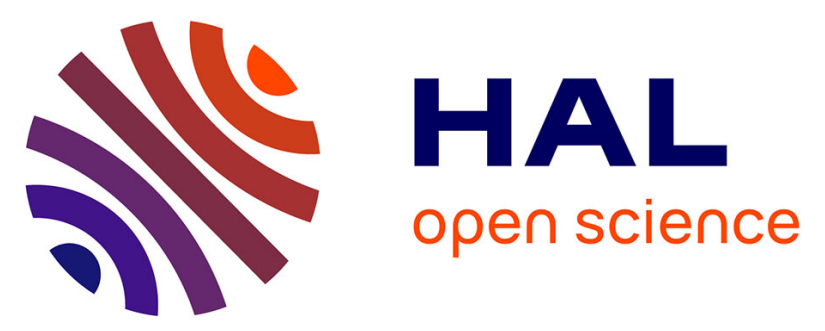

\title{
Combining NSAM and CPC concentrations to determine airborne nanoparticle count median diameter: Application to various laboratory and workplace aerosols
}

S. Bau, R. Payet, A. Toussaint, O. Witschger, A.M. Todea, C. Monz, C. Asbach

\section{To cite this version:}

S. Bau, R. Payet, A. Toussaint, O. Witschger, A.M. Todea, et al.. Combining NSAM and CPC concentrations to determine airborne nanoparticle count median diameter: Application to various laboratory and workplace aerosols. Journal of Occupational and Environmental Hygiene, 2018, 15 (6), pp.492 - 501. 10.1080/15459624.2018.1449953 . hal-01844722

\author{
HAL Id: hal-01844722 \\ https://hal.science/hal-01844722
}

Submitted on 19 Jul 2018

HAL is a multi-disciplinary open access archive for the deposit and dissemination of scientific research documents, whether they are published or not. The documents may come from teaching and research institutions in France or abroad, or from public or private research centers.
L'archive ouverte pluridisciplinaire $\mathbf{H A L}$, est destinée au dépôt et à la diffusion de documents scientifiques de niveau recherche, publiés ou non, émanant des établissements d'enseignement et de recherche français ou étrangers, des laboratoires publics ou privés. 
Combining NSAM and CPC concentrations to determine airborne nanoparticle count median diameter: application to various laboratory and workplace aerosols

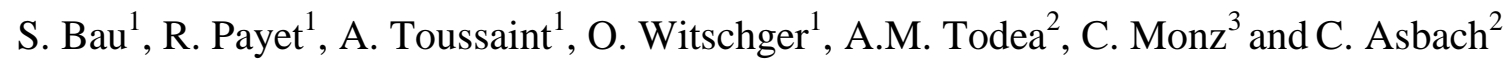

${ }^{1}$ Institut National de Recherche et de Sécurité, Laboratoire de Métrologie des Aérosols, Rue du Morvan CS 60027, 54519 Vandoeuvre, France

sebastien.bau@inrs.fr

${ }^{2}$ Institut für Energie- und Umwelttechnik e. V. (IUTA), Bliersheimer Straße 58-60, 47229 Duisburg, Germany

${ }^{3}$ Institut für Gefahrstoffforschung (IGF), Waldring 97, 44789 Bochum, Germany

Keywords: count median diameter; lung-deposited surface area concentration; NSAM/CPC

Wordcount $=4076$ 


\section{ABSTRACT}

Because nanomaterials have been increasingly developed and used in many technology and industry sectors over the last 20 years, increasing numbers of workers are likely to be exposed to airborne nanoparticles. In addition, the question of the nanomaterial characteristics that should be assessed in epidemiological studies remains open. Thus, assessing occupational exposure to airborne nanoparticles shall not only rely on mass concentration and chemical composition; key parameters, such as particle size, have to be included in measurement strategies.

We previously proposed a methodology to estimate the Count Median Diameter (CMD) of an aerosol based on the simultaneous size-integrated measurement of two particle concentrations, lung-deposited surface area and number, thanks to field-portable, commercially available aerosol instruments (Nanoparticle Surface Area Monitor / Condensation Particle Counter combination).

In addition to previous work, this study investigates the case of various polydisperse metal oxides, organic oil and salt particles in a range of CMDs from 16 to $410 \mathrm{~nm}$. Once corrected, the CMDs derived from the NSAM/CPC agree within $\pm 20 \%$ with regard to the reference electrical mobility equivalent diameter, regardless of aerosol composition, morphology, or geometric standard deviation (GSD).

Furthermore, the field-applicability of the method was tested through six sets of experimental data stemming from workplace measurement campaigns where different materials were produced and handled $\left(\mathrm{TiO}_{2}, \mathrm{SiO}_{2}, \mathrm{Ag}\right.$, Multi-Walled Carbon Nanotubes MWCNT), covering a range of CMDs between 40 and $190 \mathrm{~nm}$. All situations considered, the approach based on the combination of a NSAM and a CPC leads to a satisfying estimation of particle CMD, within $\pm 20 \%$ compared to reference CMD. 


\section{INTRODUCTION}

Due to the growing use of manufactured nanomaterials, it is likely that workers in research laboratories and industry are also increasingly being exposed to them at all points of their life cycle, from synthesis and production to downstream use, aging and disposal ${ }^{(1)}$. Although the toxicological effects of inhaled airborne nanoparticles cannot be directly correlated with their physico-chemical properties, developing and testing robust methods to determine some of the key parameters of airborne nanoparticles remains necessary.

The parameters that should be assessed to characterize airborne nanomaterials are still being debated, thus, implementing a multi-metric approach has recently been suggested ${ }^{(2-4)}$. In addition to chemical composition and number concentration, particle size is among the parameters which play a role in the potential health effects of nanoparticles ${ }^{(5)}$. This is mainly due to the role of particle diameter in its deposition in the human respiratory tract ${ }^{(6,7)}$, where inhaled nanoparticles will potentially interact.

Measuring the size of airborne nanoparticles can be achieved by time-integrated techniques, e.g. (personal) cascade impactors or diffusion batteries with subsequent SEM analysis. Size can be measured in real-time with instruments such as electrical mobility analyzers (e.g. Scanning Mobility Particle Sizer - SMPS, Fast Mobility Particle Sizer FMPS) or electrical low pressure cascade impactors (e.g. Electrical Low Pressure Impactor ELPI, ELPI+). Their lack of field-portability, complexity of use and high cost make them not ideally suited to monitor aerosols in workplaces ${ }^{(8)}$. Another option relies in the use of optical aerosol spectrometers. The latter are, however, limited to particle size approximately larger than $250 \mathrm{~nm}$. 
In the absence of size-resolving instruments, approaches based on the simultaneous measurement of size-integrated particle concentrations (number, surface area or mass) have been proposed by different authors (e.g. Woo et $\mathrm{al}^{(9)}$, Maynard ${ }^{(10)}$, Park et al ${ }^{(11)}$, Park et al ${ }^{(12)}$, Park et $\mathrm{al}^{(13)}$ ), in particular to determine the number size distribution or airborne particles.

In a recent work, Pham \& Jung ${ }^{(14)}$ combined a Condensation Particle Counter (CPC) and an Electrical Aerosol Detector (EAD, TSI) to determine particle count median diameter based on the response function of the EAD over the range from $10 \mathrm{~nm}$ to $1 \mu \mathrm{m}$ and the assumption of lognormally-distributed aerosols with a geometric standard deviation of 1.7. They tested their methodology during ambient aerosol monitoring by comparing their results to SMPS data, highlighting a good correlation $\left(\mathrm{R}^{2}=0.77\right)$ between both approaches.

We proposed and tested a methodology that relies on the simultaneous measurement of number and lung-deposited surface area (LDSA) concentrations of airborne nanoparticles to evaluate the count median diameter (CMD) of an aerosol in a previous work ${ }^{(15)}$. Polydisperse monomodal metal aerosols in a range of CMDs between 60 and $180 \mathrm{~nm}$ were used to evaluate the performance of the approach. The results highlighted that, the reference CMDs and the CMDs determined with the approach developed agree within $\pm 30 \%$. In this methodology, the number concentration is measured by a CPC, while the LDSA concentration requires the use of a unipolar diffusion charging instrument, e.g. the Nanoparticle Surface Area Monitor (NSAM).

The NSAM (TSI, model 3550) was developed to provide the fractions of the geometric surface area concentrations of particles that would deposit in either the tracheobronchial or the alveolar region of the lung. A good agreement with the ICRP deposition model ${ }^{(7)}$ has already been shown in several experimental and theoretical studies ${ }^{(16-23)}$ for various particles with sizes between 15 and $520 \mathrm{~nm}$. Levin et $\mathrm{al}^{(24)}$ investigated the behaviour of FMPS and ELPI compared to NSAM data for a set of aerosolized powder nanomaterials. They concluded that 
there is a need for increasing knowledge on the measurement of LDSA concentrations, in particular when regulatory issues are considered. In a recent study ${ }^{(25)}$, NSAM's signal was modulated through the use of two optimized trap voltages to provide the geometric surface area concentration of airborne nanoparticles.

This leads us to think that the NSAM is a robust instrument and suitable for many applications including exposure assessment. As shown in Table I, the NSAM has been implemented in different laboratory or field studies for different purposes.

It should be noted that other devices can be used to provide airborne LDSA concentration, such as the field-portable AeroTrak 9000 (TSI), as well as personal monitors ${ }^{(26)}$, like DiSCmini / miniDiSC ${ }^{(27)}$ (Testo AG, Titisee-Neustadt, Germany), NanoTracer ${ }^{(28,29)}$ (oxility b.v., Eindhoven, The Netherlands) and Partector (naneos GmbH, Windisch, Switzerland) ${ }^{(30 \text {, }}$ 31). It has been demonstrated that these devices behave similar to the $\operatorname{NSAM}^{(21-23,32,33)}$ and that wearing them as personal monitors does not affect their response ${ }^{(34)}$.

In this context and bringing new elements compared to our previous work ${ }^{(15)}$, the present study provides new results for estimating the count median diameter of airborne nanoparticles from the combined NSAM/CPC approach. In particular, this paper investigates the case of 40 polydisperse aerosols consisting of metal oxides, organic oil and salt particles. The CMDs obtained from the NSAM/CPC measurements in the laboratory were compared to SMPS data. The reference CMDs range from 16 to $410 \mathrm{~nm}$.

In addition, workplace measurement data were used to test the field applicability of the method. Because of limited SMPS transportation possibilities in France (due to legislation on radioactive sources), the data measured with an ELPI were used as reference. The workplace aerosols had CMDs in the range from 42 to $190 \mathrm{~nm}$. 


\section{MATERIALS AND METHODS}

\section{Theoretical background: establishing a relationship between the count median diameter and airborne particle number and lung-deposited surface area concentrations}

The mathematical basis of the approach was proposed and detailed elsewhere ${ }^{(15)}$, thus, only a short description of it is given in this section. The lung-deposited surface area (LDSA) concentration of an aerosol formed of spherical particles, noted $C_{S, \mathrm{LD}}$, is given by:

$C_{S, \mathrm{LD}}=C_{N} \cdot \pi \cdot d_{\bar{S}}^{2} \cdot \eta_{\mathrm{LD}}$

This equation corresponds to the product of the geometric surface area concentration ( $C_{N} \cdot \pi \cdot d_{\bar{S}}^{2}$ with $C_{N}$ the particle number concentration) and the probability ( $\eta_{\mathrm{LD}}$ ) of a particle to deposit in a given region of the respiratory apparatus. Solving equation (1) to determine the diameter of average geometric surface area $\left(d_{\bar{s}}\right)$ is complex because the particle deposition probability is size-dependent. In particular, it relies on the response function of the instrument, which has been described in previous studies for various aerosols in a range from 15 to $520 \mathrm{~nm}^{(21,22)}$. From this diameter $d_{\bar{S}}$, the corresponding count median diameter (CMD) of an aerosol can be obtained, assuming a lognormal number size distribution, according to (35):

$d_{\bar{S}}=C M D \cdot \exp \left(\ln ^{2} G S D\right)$

where GSD is the geometric standard deviation of the distribution. Thus, by combining equations 1 and 2 the CMD of airborne particles can be determined.

A panel of theoretical curves, which provide the count median diameter of an aerosol based on the ratio $C_{S, \mathrm{LD}} / C_{N}$ and the GSD of the distribution, was published by Bau et al ${ }^{(15)}$ in a range from 50 to $200 \mathrm{~nm}$. When the GSD of the aerosol is unknown, a typical value of 1.8 can 
be considered according to different authors ${ }^{(10,11,36)}$ for submicron airborne particles. Roughly, 30\% variation in the calculated CMD can be observed between cases where the GSD is known or unknown (and thus fixed at 1.8).

\section{Laboratory test aerosols}

Various test aerosols were produced in two different laboratories at INRS and IGF to investigate the applicability of the combined NSAM/CPC approach and complement the data already published by $\mathrm{Bau}$ et $\mathrm{al}^{(15)}$. The generation set-up and the characteristics of the different test aerosols are gathered in Table II and described in the sections below. The GSD used in the NSAM/CPC approach to determine the CMD of the test aerosols are the ones included in Table II.

The laboratory aerosols under study consisted of:

- metal-based agglomerates made of $\mathrm{C}, \mathrm{Ag}, \mathrm{Ti}, \mathrm{Cu}$ and Constantan and produced by spark discharge (PALAS GFG 1000 within the CAIMAN facility at $\operatorname{INRS}^{(37)}$ and PALAS GFG3000 at IGF, NanoTestCenter, Dortmund, Germany);

- ZnO supplied by a prototype of the burner-type nanoparticle generator FG2 (MoTec Konzepte $\mathrm{GmbH}$, Bochum, Germany, see Monsé et $\mathrm{al}^{(38)}$ ), where a constant solution flowrate is introduced into a flame by means of an automated syringe $(40 \mathrm{~mL} / \mathrm{h}$ for zinc acetate solution to produce $\mathrm{ZnO}$ particles, $15 \mathrm{~mL} / \mathrm{h}$ for a $5 \mathrm{~g} / \mathrm{L} \mathrm{NaCl}$ solution) and vaporized. A sheath and dilution air flow allows particle concentration to be controlled;

- Diethyl-hexyl sebacate (DEHS) and $\mathrm{CsCl}$ generated by atomization (home-built atomizer) under different solution concentrations (pure DEHS and diluted with 
isopropanol, $\mathrm{CsCl}$ concentrations of $1.25 \mathrm{~g} / \mathrm{L}$ and $80 \mathrm{~g} / \mathrm{L}$ ) and atomizer inlet pressures (IGF);

- $\mathrm{TiO}_{2} \mathrm{P} 25$ produced by a Rotating Brush Generator (PALAS RBG 1000) operating at $1200 \mathrm{rpm}$ under 1 bar inlet pressure and constant elevation speed of $3 \mathrm{~mm} / \mathrm{h}$ (INRS).

Airborne particles were simultaneously measured by means of a Condensation Particle Counter (CPC, Grimm model 5.403, $\mathrm{d}_{50}=7.5 \mathrm{~nm}^{(39)}$ or TSI model $3007, \mathrm{~d}_{50}=10.5 \mathrm{~nm}^{(40)}$ ) and a Nanoparticle Surface Area Monitor (NSAM, TSI model 3550), as stated in Table III. In parallel, airborne particle number size distributions were measured by a SMPS (Table III) to provide the reference CMD and GSD values.

\section{Workplace aerosols}

In the framework of assessing occupational exposure to airborne nanoparticles, different workplaces were investigated, where both NSAM and CPC measurements were performed in parallel. The six different sets of experimental data stemming from workplace measurement campaigns are (Table IV):

- aerosols measured in a plant that produces both pigment grade $\mathrm{TiO}_{2}$ and nano- $\mathrm{TiO}_{2}$ as powders during bagging operations ${ }^{(41)}$ — workplace " $\mathrm{A}$ ";

- aerosols emitted during discharging bags of nano- $\mathrm{TiO}_{2}$ powder into an industrial funnel for further incorporation into cosmetic products - workplace "B";

- aerosols measured in a research laboratory during dry sandpapering of a reactor producing nanocomposite thin films embedded with silver nanoparticles ${ }^{(42)}$ workplace "C";

- aerosols released during automated extrusion of a polymer containing Multi-Walled Carbon Nanotubes (MWCNT) ${ }^{(43)}$ — workplace "D"; 
- aerosols released in a workshop producing photocatalytic media made of amorphous silica fibers felt with titanium dioxide (data not published yet) — workplace "E".

Except for case "E", the CMD given in Table IV do not correspond to the size of the materials handled.

As stated earlier, the GSD of the workplace aerosols can be assumed to be 1.8 according to different authors. The CPC used in parallel of the NSAM was a Grimm model 5.403 for workplaces "A" and "E", a TSI model 3007 for workplaces "B" and "D", and a TSI P-Trak for workplace "C". Although these counters have different size ranges, the aim of this paper is to experience the field-feasibility of the approach, whatever the CPC used to provide particle number concentration.

\section{Considerations regarding the reference CMD}

For the case of laboratory test aerosols, the reference CMDs considered are determined from the adjusted lognormal law based on number size distribution measured by a SMPS, all of them being monomodal. Indeed, the count median diameter of a lognormal size distribution can be derived from the modal diameter and the geometric standard deviation of the distribution according to ${ }^{(44)}$ :

$C M D=d_{\text {mode }} \cdot \exp \left(\ln ^{2} G S D\right)$

Thus, the reference CMD is an electrical mobility equivalent diameter. Although NSAM is not based on electrical migration of charged particles in an electric field, it was demonstrated that the charging efficiency, and thus the response of the instrument, scales with the electrical mobility diameter ${ }^{(45,46)}$.

Defining the reference count median diameter for the case of workplace aerosols is different. Due to their measurement principle based on Boltzmann electrical state-of-charge 
equilibrium, SMPS are commonly equipped with radioactive sources (except recent models using a soft X-ray charger). In France, the regulation relating to holding and transport of radioactive sources makes it difficult to perform SMPS measurements in workplaces. Instead, data stemming from an Electrical Low Pressure Impactor (ELPI, Dekati) were considered to provide the reference modal aerodynamic diameter. The latter modal aerodynamic diameters (as defined by the geometric diameter of the modal impaction stage) were then converted into mobility equivalent modal diameter considering spherical particles with unit density, and further converted into CMD by applying equation 3 to ensure comparability with the NSAM/CPC-based CMD with GSD = 1.8.

The reader's attention shall be drawn to the operation investigated for case "B", where aerosol sampling was performed directly in the plume, contrary to other situations considered in this paper in which aerosols were sampled in the surrounding area of the workers. Thus, it can be considered that the aerosol of workplace " $\mathrm{B}$ " only consists of $\mathrm{TiO}_{2}$, which allows a particle density of $\sim 4 \mathrm{~g} / \mathrm{cm}^{3}$ to be used for the conversion of the modal aerodynamic diameter into mobility equivalent diameter.

It is also worth mentioning that data from ELPI were not further specifically treated (e.g. lognormal optimization, data inversion, etc). Although particle density influences the number concentration in each channel of the ELPI (e.g. the number size distribution as well as the total number concentration), data published by Charvet et $\mathrm{al}^{(47)}$ for thermal metal spraying aerosols show that the modal diameter is almost constant (roughly $\pm 20 \%$ ), whatever the particle density considered in ELPI data post-treatment (calculation of the number size distribution based on the currents measured). In addition, some of the workplace aerosols defined in Table IV presented a second mode in their number size distribution in the micron size range (aerosols "A1", “A2"). The latter populations, when present according to the ELPI data, were not considered since (1) the NSAM is equipped with an inlet cyclone $\left(\mathrm{d}_{50}=1 \mu \mathrm{m}\right.$ 
aerodynamic), (2) they are probably not efficiently taken into account in the CPC number concentration, and (3) their contribution to the overall number concentration as measured by the ELPI is below $10 \%$.

\section{NSAM calibration}

To ensure the reliability of LDSA measurements, experimental data stemming from NSAM were compared to theoretical LDSA concentrations calculated according to:

$\mathrm{C}_{\mathrm{S}, \mathrm{LD}}=\Sigma_{\mathrm{d}_{\mathrm{p}}} \mathrm{C}_{\mathrm{N}}\left(\mathrm{d}_{\mathrm{p}}\right) \cdot \pi \cdot \mathrm{d}_{\mathrm{p}}{ }^{2} \cdot \eta_{\mathrm{LD}}\left(\mathrm{d}_{\mathrm{p}}\right)$

where $\mathrm{C}_{\mathrm{N}}\left(\mathrm{d}_{\mathrm{p}}\right)$ is the number size distribution based on SMPS-fitted data. Three cases covering the range of LDSA concentrations are reported in Table V.

According to Table V, it can be considered that with the given assumptions, NSAM and SMPS data are in good agreement. The biases, even below $\pm 10 \%$, can be partly explained by the use of a lognormal fit of SMPS data to compute the corresponding LDSA concentration and the calibration factor of the NSAM.

\section{RESULTS AND DISCUSSION}

Although both alveolar ('alv') and tracheobronchial ('tb') regions of the respiratory tract can be considered, only the 'alv' configuration of the NSAM was used in the experiments carried out in this study. In previous work it was noticed that equivalent results are observed for both configurations ${ }^{(15)}$. Due to potential biases in the response of the NSAM for larger particles, it is worth mentioning that the combined NSAM/CPC approach is considered to be applicable for particles up to roughly $500 \mathrm{~nm}$ in diameter. 


\section{Laboratory test aerosols}

Figure 1 presents the results obtained when sampling the polydisperse aerosols $(n=40$,

see Table II) generated in the laboratory, with reference CMDs ranging from 16 to $411 \mathrm{~nm}$. NSAM/CPC-based and reference CMDs are highly correlated. More precisely, Figure 1 shows that CMD based on the NSAM/CPC approach tend to be lower than the corresponding reference CMD by a nearly constant relative deviation between $-30 \%$ and $-40 \%$. No systematic effect of airborne particle composition, morphology or CMD can be noticed.

To further interpret the data displayed in Figure 1, the ratio $R$ is defined as:

$$
R=\frac{C M D_{\mathrm{NSAM} / \mathrm{CPC}}}{C M D_{\text {reference }}}
$$

The closer to unity the ratio is, the better the agreement between the CMD based on the NSAM/CPC approach and the CMD based on SMPS data (equation 3). The median ratio is found to be $\mathrm{R}_{50}=0.66$, with a narrow $50 \%$-confidence interval in the range 0.61-0.69 and a 95\%-confidence interval in the range 0.54-0.74, which attests the good fidelity of the NSAM/CPC approach. This systematic bias remains unexplained yet. Therefore, this step highlights the need for prior verification of the combined NSAM/CPC approach by comparison to SMPS reference data. This step being carried out, users are able to determine the correction factor $\left(1 / \mathrm{R}_{50}\right)$ of their own specimen combination to further implement the approach proposed.

Based on our experimental results, considered as representative for a variety of aerosols, a correction factor of $1 / \mathrm{R}_{50}=1 / 0.66=1.52$ can be introduced to make the NSAM/CPC-based CMD fit to the reference CMD. Applying this correction factor yields a 50\%-confidence interval in the range 0.93-1.04 and a 95\%-confidence interval in the range 0.81-1.12. Thus, it can be considered that the CMD of airborne particles can be determined from the combined NSAM/CPC approach within $\pm 20 \%$. 


\section{Workplace aerosols}

To experience the feasibility of the approach in workplace situations, a series of occupational environments has been considered, as stated in Table IV. The average particle number size distributions measured by the ELPI are presented in Figure 2.

Figure 2 highlights the variability in workplace aerosol number size distribution; each of them being quite singular compared to each other. It can be noticed that workplace aerosols were not found to be lognormal. Thus, this can lead to biases because the method relies on the assumption of a lognormal size distribution with GSD of 1.8. Based on the distributions measured by the ELPI, the modal aerodynamic diameters considered were the ones corresponding to the geometric aerodynamic diameter of the modal impaction stage. The latter is then converted into mobility equivalent modal diameter, and further into CMD according to equation 3 .

Accounting for the presence of the cyclone upstream the NSAM, it is reminded that only the submicron mode of the ELPI number size distribution is considered. The CMDs derived from the NSAM/CPC combination are compared to the reference CMD based on ELPI measurements in Figure 3.

In general, Figure 3 shows a correlation between the CMDs based on the NSAM/CPC ratio and the ELPI-based ones. Out of the 6 cases considered, the relative discrepancies between the CMDs based on the NSAM/CPC approach ('raw') and the reference are $-42 \%$. This corroborates previous observations for laboratory test aerosols (Figure 1), where the median relative discrepancy was found to be $-34 \%$. When the correction factor of 1.52 derived from laboratory data is applied to NSAM/CPC-based CMDs ('corrected'), the relative discrepancies range from $-23 \%$ to $+9 \%$, with an average deviation of $-11 \%$. 
More particularly, the aerosols measured in workplace " $\mathrm{A}$ ", where nano- $\mathrm{TiO}_{2}$ powder is filled into big bags, are highly polydisperse, as can be seen in Figure 2. The relative discrepancies between the two CMD - the one stemming from the NSAM/CPC approach and the modal diameter based on ELPI data - are $-18 \%$ and $-6 \%$ for cases "A1" and "A2", respectively, which is satisfactory.

The case of the aerosol measured in workplace "B", which involves discharging a $10 \mathrm{~kg}$ bag of powder of nano- $\mathrm{TiO}_{2}$, corresponds to a relative deviation of $-11 \%$ in terms of CMD. This aerosol is monomodal, not necessarily lognormal (tail due to smaller particles), with a GSD likely larger than 1.8 .

Dry sandpapering of a reactor producing nanocomposite thin films embedded with silver nanoparticles, noted "C", produced monomodal aerosols with a quite low GSD. The latter GSD is found to be near 1.8, which corresponds to the assumption in the NSAM/CPC approach. In this case, the CMD derived from the NSAM/CPC combination underestimates particle modal diameter by $-23 \%$ compared to the reference.

The aerosol measured in workplace " $D$ " during the automated extrusion of a polymer containing MWCNT presents a number size distribution below $400 \mathrm{~nm}$ aerodynamic. Based on ELPI data (Figure 2), it is likely that the modal aerodynamic diameter is below the lowest stage cutpoint, i.e. below $30 \mathrm{~nm}$ aerodynamic. We hypothesized the modal aerodynamic diameter is equal to $30 \mathrm{~nm}$ (corresponding CMD of $42 \mathrm{~nm}$ ). Although this might lead to an overestimation of the true modal diameter of the aerosol, the CMD based on the NSAM/CPC combination is found to be $46 \mathrm{~nm}$ (relative discrepancy of $+9 \%$ ), which is in line with the abovementioned assumption.

Aerosols observed in workplace "E" mainly consisted of amorphous silica aggregates with a fractal-like morphology. As for workplace "C", the aerosol from workplace "E" is quite well described by a lognormal aerosol with a GSD of 1.8, as depicted in Figure 2. The CMD 
stemming from the NSAM/CPC approach tends to underestimate the reference modal diameter by about $-20 \%$, which is considered to be satisfactory.

Whatever the situation considered, Figure 3 suggests that the approach based on the combination of a NSAM and a CPC leads to a satisfying estimation of particle CMD (roughly $\pm 20 \%$ ). Although few in number, the occupational environments investigated covered a wide range of modal aerodynamic diameters, ranging roughly from 30 to $300 \mathrm{~nm}$, i.e. CMD ranging from 40 to $190 \mathrm{~nm}$. In addition, it should be kept in mind the assumptions required to apply the approach: (1) lognormal size distribution, (2) GSD of 1.8 used for both the calculation of the reference CMD and the NSAM/CPC-based one, and (3) particle density taken equal to $1 \mathrm{~g} / \mathrm{cm}^{3}$ (or the one of the raw material when for sure different than $1 \mathrm{~g} / \mathrm{cm}^{3}$ ) to convert ELPI-based aerodynamic into mobility equivalent diameter.

\section{CONCLUSION}

This study focused on testing the performance of the NSAM/CPC combination to estimate the count median diameter of aerosols over the particle size range from 15 to $410 \mathrm{~nm}$. Given that the NSAM (1) has been thoroughly investigated and characterized, (2) is a robust instrument, and (3) is suitable for many applications such as occupational and environmental monitoring, it has been involved in many laboratory or field studies for different purposes. Since it is likely that many researcher teams own a NSAM worldwide, proposing an approach allowing the CMD of airborne particles to be determined based on NSAM measurement is relevant. Indeed, in the absence of any data with regards to particle size (distribution), this approach can be used as a screening tool to detect the presence of nanoparticles.

In a first step, our work was carried out using test aerosols generated in the laboratory. The polydisperse test aerosols covered a wide range of CMDs (from 16 to $410 \mathrm{~nm}$ ), chemical natures (mineral, organic), and morphologies (cubic, spherical, fractal-like). Experimental 
results highlight that the approach based on the NSAM/CPC tends to underestimate the CMD by a constant factor of 0.66 . This led to the introduction of a correction factor of $\sim 1.5$ to improve the comparability of NSAM/CPC-based and reference CMDs. A setup involving SMPS and NSAM/CPC laboratory data can be carried out by the users to determine the constant factor of a given specimen combination prior to the implementation of the approach proposed.

In a second step, the feasibility of the method was investigated in workplace situations. Six sets of experimental data stemming from workplace measurement campaigns $\left(\mathrm{TiO}_{2}, \mathrm{SiO}_{2}\right.$, Ag, MWCNT) were considered; the corresponding modal aerodynamic diameters ranged between 30 and $300 \mathrm{~nm}$. Assuming the GSD of the aerosols to be 1.8, the CMDs stemming from 'corrected' NSAM/CPC combination were found to in reasonable agreement $( \pm 20 \%)$ as the CMDs obtained from the conversion of ELPI-based reference data into electrical mobility CMD; this finding suggests the possible field-applicability of the approach.

Overall, results between the NSAM/CPC combination and reference instrument indicated a strong positive correlation, independent of the type of aerosol.

Although not tested here, we can speculate that this approach is also valid for other diffusion charging devices that do not provide particle size, such as the AeroTrak 9000 or the Electrical Aerosol Detector. Thus, further experiments involving such devices are required to validate the applicability of the approach to them.

\section{ACKNOWLEDGEMENTS}

Part of the experimental results presented in this paper were obtained within the framework of the European Mandate M/461. 


\section{REFERENCES}

\section{Savolainen, K., P. Pylkkänen, H. Norppa, G. Falck, H. Lindberg, T. Tuomi et al.:}

Nanotechnologies, engineered nanomaterials and occupational health and safety - A review. Safety Science 48: 957-963 (2011).

2 Shepard, M.N., and S. Brenner: An occupational exposure assessment for engineered nanoparticles used in semiconductor fabrication. Ann. Occup. Hyg. 58(2): 251-265 (2013).

3 O'Shaughnessy, P.T.: Occupational health risk to nanoparticulate exposure. Environ. Sci.: Processes Impacts 15: 49-62 (2013).

4 Gordon, S.C., J.H. Butala, J.M. Carter, A. Elder, T. Gordon, G. Gray et al.: Workshop report: Strategies for setting occupational exposure limits for engineered nanomaterials. Regul. Toxicol. Pharm. 68: 305-311 (2014).

5 Wang, J., C. Asbach, H. Fissan, T. Hülser, T.A.J. Kuhlbusch, D. Thompson et al.: How can nanobiotechnology oversight science and industry: examples from environmental, health, and safety studies of nanoparticles (nano-EHS). Journal of Nanoparticle Research 13: 1373-1387 (2011)

6 Broday, D.M., and R. Rosenzweig: Deposition of fractal-like soot aggregates in the human respiratory tract. Journal of Aerosol Science 42: 372-286 (2011).

7 ICRP. Publication 66: Human respiratory tract model for radiological protection: Oxford: Pergamon (1994).

8 Leskinen, J., J. Joutsensaari, J. Lyyränen, J. Koivisto, J. Ruusunen, M. Järvelä et al.: Comparison of nanoparticle measurement instruments for occupational health applications. Journal of Nanoparticle Research 14: 718-733 (2012). 
9 Woo, K.S., D.R. Chen, D.Y.H. Pui, and W.E. Wilson: Use of continuous measurements of integral aerosol parameters to estimate particle surface area. Aerosol Science and Technology 34: 57-65 (2001).

10 Maynard, A.D.: Estimating aerosol surface-area from number and mass concentration measurements. Ann. Occup. Hyg. 47: 123-144 (2003).

11 Park, J.Y., P.C. Raynor, A.D. Maynard, L.E. Eberly, and G. Ramachandran: Comparison of two estimation methods for surface area concentration using number concentration and mass concentration of combustion-related ultrafine particles. Atmospheric Environment 43: 502-509 (2009).

12 Park, J.Y., G. Ramachandran, P.C. Raynor, and S.W. Kim: Estimation of surface area concentration of workplace incidental nanoparticles based on number and mass concentrations. Journal of Nanoparticle Research 13: 4897-4911 (2011).

13 Park, D., S. Kim, M. An, and J. Hwang: Real-time measurement of submicron aerosol particles having a lognormal size distribution by simultaneously using unipolar diffusion charger and unipolar field charger. Journal of Aerosol Science 38: 1240-1245 (2007).

14 Pham, L., and H.S. Jung: Alternative metrics for spatially and temporally resolved ambient particle monitoring. Journal of Aerosol Science 102: 96-104 (2016).

15 Bau, S., O. Witschger, F. Gensdarmes, and D. Thomas: Determining the count median diameter of nanoaerosols by simultaneously measuring their number and lung deposited surface area concentrations. Journal of Nanoparticle Research 15: 2104 (2013).

16 Asbach, C., H. Fissan, B. Stahlmecke, T.A.J. Kuhlbusch, and D.Y.H. Pui: Conceptual limitations and extensions of lung-deposited Nanoparticle Surface Area Monitor (NSAM). Journal of Nanoparticle Research 11: 101-109 (2009). 
17 Fissan, H., S. Neumann, A. Trampe, D.Y.H. Pui, and W.G. Shin: Rationale and principle of an instrument measuring lung deposited nanoparticle surface area. Journal of Nanoparticle Research 9: 53-59 (2007).

18 Shin, W.G., D.Y.H. Pui, H. Fissan, S. Neumann, and A. Trampe: Calibration and numerical simulation of Nanoparticle Surface Area Monitor (TSI model 3550 NSAM). Journal of Nanoparticle Research 9: 61-69 (2007).

19 Mokhtar, M.A., R.E. Jayaratne, L. Morawska, M. Mazaheri, N. Surawski, and G. Buonanno: NSAM-derived total surface area versus SMPS-derived "mobility equivalent" surface area for different environmentally relevant aerosols. Journal of Aerosol Science 66: 111 (2013).

20 Leavey, A., J. Fang, M. Sahu, and P. Biswas: Comparison of measured particle lungdeposited surface area concentrations by an AeroTrak 9000 using size distribution measurements for a range of combustion aerosols. Aerosol Science and Technology 47: 966978 (2013).

21 Bau, S., O. Witschger, F. Gensdarmes, and D. Thomas: Response of three instruments devoted to surface-area for monodisperse and polydisperse aerosols in molecular and transition regimes. Journal of Physics: Conference Series 304: 012015 (2011).

22 Bau, S., O. Witschger, F. Gensdarmes, and D. Thomas: Evaluating three direct-reading instruments based on diffusion charging to measure surface area concentrations in polydisperse nanoaerosols in molecular and transition regimes. Journal of Nanoparticle Research 14: 1217-1233 (2012).

23 Todea, A.M., S. Beckmann, H. Kaminski, and C. Asbach: Accuracy of electrical aerosol sensors measuring lung deposited surface area concentrations. Journal of Aerosol Science 89: 96-109 (2015). 
24 Levin, M., O. Witschger, S. Bau, E. Jankowska, I.K. Koponen, A.J. Koivisto et al.: Can we trust real-time measurements of lung deposited surface area concentrations in dust from powder nanomaterials? Aerosol and Air Quality Research in press: 1-13 (2016).

25 Cao, L.N.Y., and D.Y.H. Pui: A novel weighted sum method to measure particle geometric surface area in real-time. Journal of Aerosol Science 117: 11-23 (2018).

26 Asbach, C., C. Alexander, S. Clavaguera, D. Dahmann, H. Dozol, B. Faure et al.: Review of measurement techniques and methods for assessing personal exposure to airborne nanomaterials in workplaces. Science of the Total Environment 603-604: 793-806 (2017).

27 Fierz, M., C. Houle, P. Steigmeier, and H. Burtscher: Design, calibration, and field performance of a Miniature Diffusion Size Classifier. Aerosol Science and Technology 45(1): $1-10(2011)$.

28 Marra, J., M. Voetz, and H.J. Kiesling: Monitor for detecting and assessing exposure to airborne nanoparticles. Journal of Nanoparticle Research 12: 21-37 (2010).

29 Marra, J.: Using the Aerasense NanoTracer for simultaneously obtaining several ultrafine particle exposure metrics. Journal of Physics: Conference Series 304(1): 012010 (2011).

30 Fierz, M., D. Meier, P. Steigmeier, and H. Burtscher: Aerosol Measurement by Induced Currents. Aerosol Science and Technology 48(4): 350-357 (2014).

31 Fierz, M., D. Meier, P. Steigmeier, and H. Burtscher: Miniature nanoparticle sensors for exposure measurement and TEM sampling. Journal of Physics: Conference Series 617: $012034(2015)$.

32 Todea, A.M., S. Beckmann, H. Kaminski, D. Bard, S. Bau, S. Clavaguera et al.: Intercomparison of personal monitors for nanoparticles exposure at workplaces and in the environment. Science of the Total Environment 605-606: 929-945 (2017). 
33 Bau, S., B. Zimmermann, R. Payet, and O. Witschger: Laboratory study of the performance of the miniature Diffusion Size Classifier (DiSCmini) for various aerosols in the 15-400 nm range. Environmental Science: Processes and Impacts 17: 261-269 (2015).

34 Asbach, C., V. Neumann, C. Monz, D. Dahmann, M. van Tongeren, C. Alexander et al.: On the effect of wearing personal nanoparticle monitors on the comparability of personal exposure measurements. Environmental Science: Nano 4: 233-243 (2017).

35 Hatch, T., and S.P. Choate: Statistical description of the size properties of non-uniform particulate substances. J. Franklin Inst. 207: 369-387 (1929).

36 Harris, S.J., and M. Maricq: Signature Size Distributions for Diesel and Gasoline Engine Exhaust Particulate Matter. Aerosol Science and Technology 32: 749-764 (2001).

37 Jacoby, J., S. Bau, and O. Witschger: CAIMAN: a versatile facility to produce aerosols of nanoparticles. Journal of Physics: Conference Series 304: 012014 (2011).

38 Monsé, C., C. Monz, D. Dahmann, C. Asbach, B. Stahlmecke, N. Lichtenstein et al.: Development and evaluation of a nanoparticle generator for human inhalation studies with airborne zinc oxide. Aerosol Science and Technology 48: 418-426 (2014).

39 Heim, M., G. Kasper, G.P. Reischl, and C. Gerhart: Performance of a new commercial electrical mobility spectrometer. Aerosol Sci Technol 38(S2): 3-14 (2004).

40 Mordas, G., H.E. Manninen, T. Petäjä, P.P. Aalto, K. Hämeri, and M. Kulmala: On Operation of the Ultra-Fine Water-Based CPC TSI 3786 and Comparison with Other TSI Models (TSI 3776, TSI 3772, TSI 3025, TSI 3010, TSI 3007). Aerosol Science and Technology 42(2): 152-158 (2008).

41 Witschger, O., R. Wrobel, B. Bianchi, and S. Bau: Potential for exposure during bagging operations in a plant that produces both pigment grade $\mathrm{TiO}_{2}$ and nano- $\mathrm{TiO}_{2}$ as powders. International Conference on Safe Production and Use of nanomaterials, Nanosafe $2010(2010)$. 
42 Witschger, O., S. Bau, B. Bianchi, R. Wrobel, and V. Matera: Potential for exposure during cleanout operations of a reactor producing nanocomposite thin films embedded with silver nanoparticles. 5th International Symposium on Nanotechnology, Occupational and Environmental Health, NanOEH 2011 (2011).

43 Möhlmann, C., J. Pelzer, O. Witschger, S. Bau, and B. R'mili: Characterization of aerosols released during handling or processing operations of MWCNTs. International Congress on Safety of Engineered Nanoparticles and Nanotechnologies, SENN 2012 (2012).

44 Hinds, W.C. Aerosol Technology. Properties, behavior and measurement of airborne particles (2nd Edition): New York: John Wiley \& Sons, 483 p. (1999).

45 Todea, A.M., S. Beckmann, H. Kaminski, and C. Asbach: Accuracy of electrical sensors measuring lung deposited surface area concentrations. Journal of Aerosol Science 89: 96-109 (2015).

46 Fissan, H., C. Asbach, H. Kaminski, and T.A.J. Kuhlbusch: Total Surface Area Concentration Measurements of Nanoparticles in Gases with an Electrical Sensor. Chemie Ingenieur Technik 84: 365-372 (2012).

47 Charvet, A., S. Bau, D. Bémer, and D. Thomas: On the importance of density in ELPI data post-treatment. Aerosol Science and Technology 49: 1263-1270 (2015).

48 Buonanno, G., L. Morawska, and L. Stabile: Exposure to welding particles in automotive plants. Journal of Aerosol Science 42: 295-304 (2011).

49 Cheng, Y.H., Y.C. Chao, C.H. Wu, C.J. Tsai, S.N. Uang, and T.S. Shih: Measurements of ultrafine particle concentrations and size distributions in an iron foundry. $J$. Hazard. Mater. 158: 124-130 (2008).

50 McGarry, P., S. Clifford, L.D. Knibbs, C. He, and L. Morawska: Application of multimetric approach to characterization of particle emissions from nanotechnology and non- 
nanotechnology processes. Journal of Occupational and Environmental Hygiene 13: D175D197 (2016).

51 Gomes, J.F., P.C. Albuquerque, R.M. Miranda, T.G. Santos, and M.T. Vieira: Comparison of deposited surface area of airborne ultrafine particles generated from two welding processes. Inhalation Toxicology 24(11): 774-781 (2012).

52 Avino, P., M. Manigrasso, P. Pandolfi, C. Tornese, D. Settimi, and N. Paolucci: Submicron particles during macro- and micro-weldings procedures in industrial indoor environments and health implications for welding operators. Metals 2015(5): 1045-1060 (2015).

53 Wang, Y.F., P.J. Tsai, C.W. Chen, D.R. Chen, and D.J. Hsu: Using a modified electrical aerosol detector to predict nanoparticle exposures to different regions of the respiratory tract for workers in a carbon black manufacturing industry. Environ. Sci. Technol. 44: 6767-6774 (2010).

54 Sillanpää, M., M.D. Geller, H.C. Phuleria, and C. Sioutas: High collection efficiency electrostatic precipitator for in vitro cell exposure to concentrated ambient particulate matter (PM). Journal of Aerosol Science 39: 335-347 (2008).

55 Westerdahl, D., X. Wang, X. Pan, and K.M. Zhang: Characterization of on-road vehicle emission factors and microenvironmental air quality in Beijing, China. Atmospheric Environment 43: 697-705 (2009).

56 Buonanno, G., L. Morawska, L. Stabile, and A. Viola: Exposure to particle number, surface area and PM concentrations in pizzerias. Atmospheric Environment 44: 3963-3969 (2010).

57 Okuda, T., H. Yamazaki, K. Hatoya, N. Kaneyasu, A. Yoshino, A. Takami et al.: Factors controlling the variation of aerosol surface area concentrations measured by a diffusion charger in Fukuoka, Japan. Atmosphere 7(33): doi: 10.3390/atmos7030033 (2016). 
58 Reche, C., M. Viana, M. Brines, N. Pérez, D. Beddows, A. Alastuey et al.: Determinants of aerosol lung-deposited surface area variation in an urban environment. Science of the Total Environment 517: 38-47 (2015).

59 Kuuluvainen, H., T. Rönkkö, A. Järvinen, S. Saari, P. Karjalainen, T. Lähde et al.: Lung deposited surface area size distributions of particulate matter in different urban areas. Atmospheric Environment 136: 105-113 (2016).

60 Li, L., Z. Zuo, D.A. Japuntich, and D.Y.H. Pui: Evaluation of filter media for particle number, surface area and mass penetrations. Ann. Occup. Hyg. 56(5): 581-594 (2012).

61 Koivisto, A.J., M. Aromaa, I.K. Koponen, W. Fransman, K.A. Jensen, J. Mäkelä et al.: Workplace performance of a loose-fitting powered air purifying respirator during nanoparticle synthesis. Journal of Nanoparticle Research 17: 177 (2015).

62 Geiss, O., I. Bianchi, and J. Barrero-Moreno: Lujng-deposited surface area concentration measurements in selected occupational and non-occupational environments. Journal of Aerosol Science 96: 24-37 (2016).

63 Asbach, C., H. Kaminski, H. Fissan, C. Monz, D. Dahmann, S. Mülhopt et al.: Comparison of four mobility particle sizers with different time resolution for stationary exposure measurements. J. Nanopart. Res 11: 1593-1609 (2009).

64 Dahmann, D., G. Riediger, J. Schlatter, A. Wiedensohler, S. Carli, A. Graff et al.: Intercomparison of mobility particle sizers (MPS). Gefahrstoffe, Reinhaltung der Luft 61(10): $423-428$ (2001). 


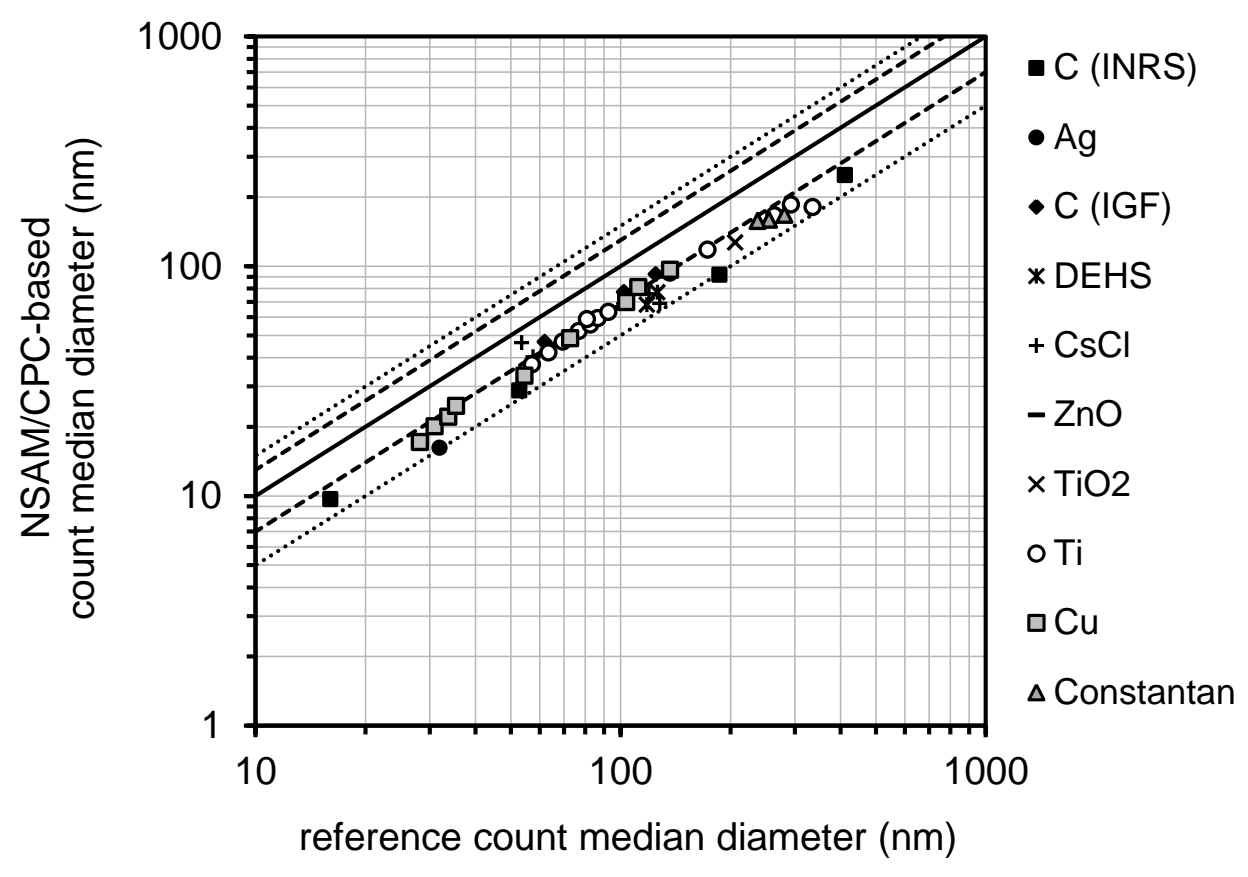

Figure 1. Comparison between the CMDs determined with the NSAM/CPC approach and the reference CMDs for various polydisperse test aerosols generated in the laboratory. The solid line corresponds to the 1:1 line, the dashed lines represent $\pm 30 \%$ deviation and the dotted lines display $\pm 50 \%$ deviation. 

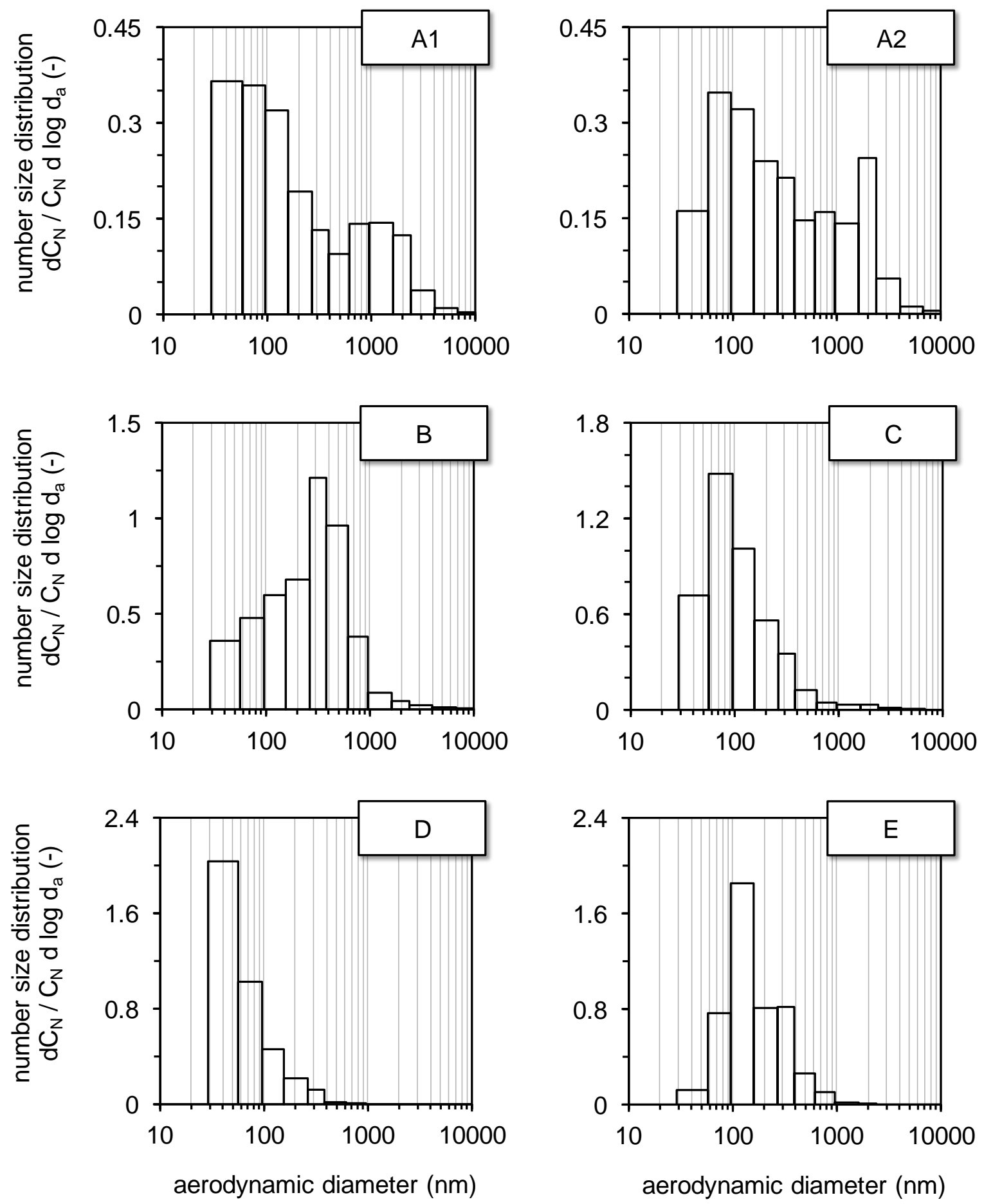

Figure 2. Average number size distribution measured by the ELPI for the various workplace aerosols considered. 


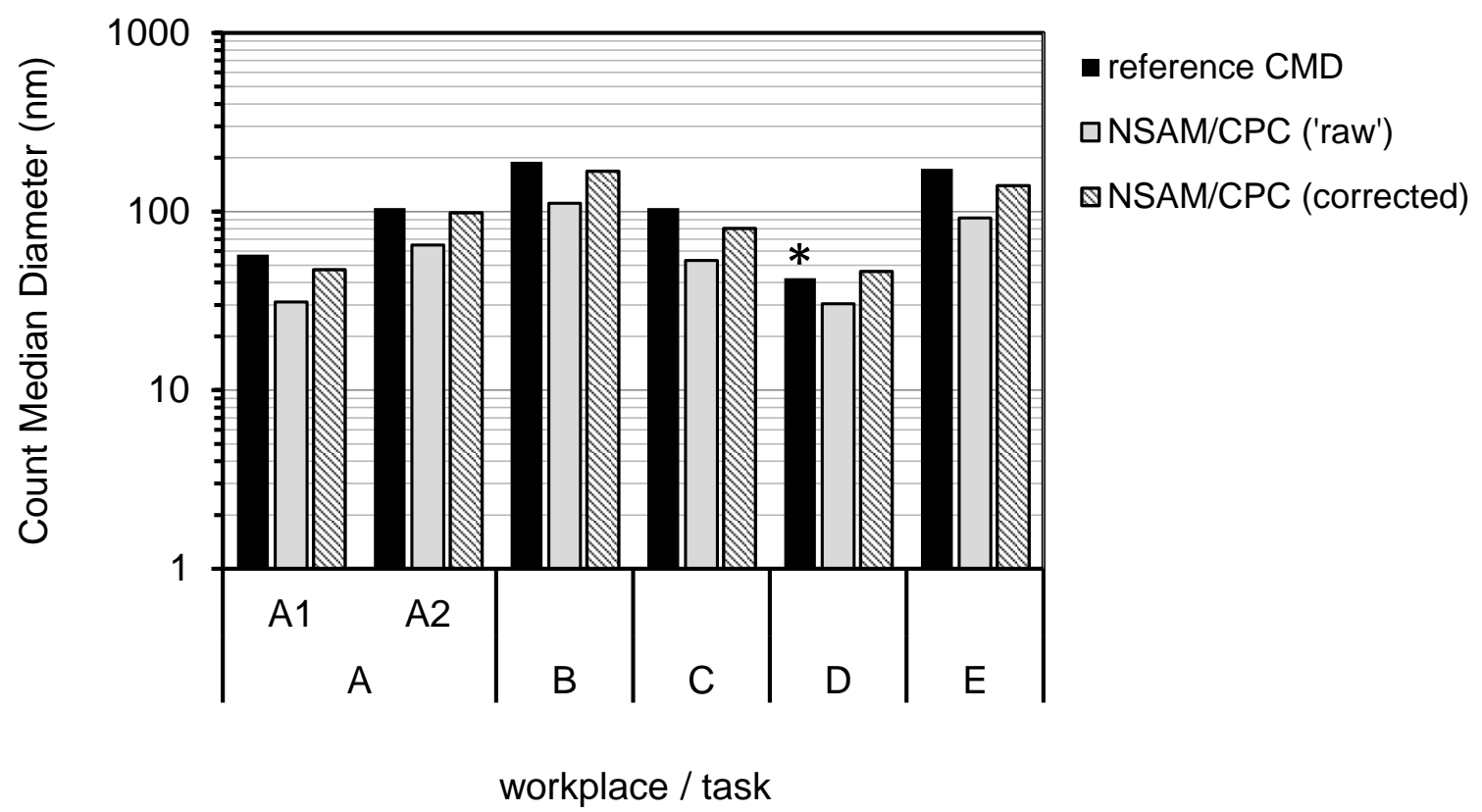

Figure 3. Comparison between the CMD based on the NSAM/CPC approach and the reference CMD based on ELPI number size distribution for various workplace aerosols. The asterix $(*)$ corresponds to a modal aerodynamic diameter likely below $30 \mathrm{~nm}$, i.e. reference CMD likely below $42 \mathrm{~nm}$. 
Table 1. Examples of NSAM's Use (Non-Exhaustive List)

\begin{tabular}{|c|c|}
\hline investigators & situation \\
\hline Buonanno et $\mathrm{al}^{(48)}$ & automobile plants \\
\hline Cheng et al ${ }^{(49)}$ & iron foundry \\
\hline McGarry et al ${ }^{(50)}$ & $\begin{array}{l}\text { laser printers operation, extruder process, clay } \\
\text { process, MWCNT decanting, SWCNT synthesis }\end{array}$ \\
\hline Gomes et $\mathrm{al}^{(51)}$, Avino et $\mathrm{al}^{(52)}$ & welding processes \\
\hline Wang et $\mathrm{al}^{(53)}$ & black carbon manufacturing \\
\hline 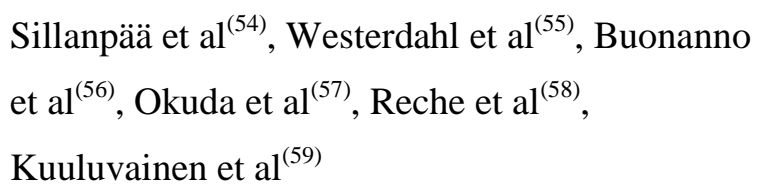 & atmospheric aerosol monitoring \\
\hline Li et al ${ }^{(60)}$, Koivisto et al ${ }^{(61)}$ & filtration performance evaluation \\
\hline Geiss et $\mathrm{al}^{(62)}$ & $\begin{array}{l}\text { occupational (welding, car journey, etc.) and non- } \\
\text { occupational (3D-printer, incense, candle etc.) } \\
\text { environments }\end{array}$ \\
\hline
\end{tabular}


Table 2. Characteristics of the 40 Test Aerosols Generated in the Laboratory

\begin{tabular}{ccccc}
\hline aerosol generator (test center) & material & $\begin{array}{c}\text { range of reference } \\
\text { CMD (nm) }\end{array}$ & range of GSD (-) & $n$ \\
\hline spark discharge (INRS) & $\mathrm{C}$ & $16-411$ & $1.50-1.58$ & 4 \\
& $\mathrm{Ag}$ & 32 & 1.41 & 1 \\
& $\mathrm{Ti}$ & $57-335$ & $1.46-1.81$ & 13 \\
& $\mathrm{Cu}$ & $28-136$ & $1.45-1.58$ & 9 \\
spark discharge (IGF) & $\mathrm{Constantan}$ & $236-281$ & $1.62-1.69$ & 3 \\
atomizer (IGF) & $\mathrm{C}$ & $62-125$ & $1.62-1.80$ & 3 \\
& $\mathrm{CsCl}$ & $58-120$ & $1.84-2.13$ & 3 \\
rotating brush generator (INRS) & $\mathrm{DEHS}$ & $118-126$ & $1.64-1.75$ & 2 \\
burner (IGF) & $\mathrm{TiO}$ & 206 & 2.09 & 1 \\
& $\mathrm{ZnO}$ & 98 & 1.48 & 1 \\
\hline
\end{tabular}


Table 3. Instruments Used in the Different Setups for the Measurement of Particle Reference CMD, Number and Lung-Deposited Surface Area Concentrations of Test Aerosols

\begin{tabular}{|c|c|c|c|}
\hline & & INRS & IGF \\
\hline \multirow{3}{*}{$\begin{array}{l}\text { Number } \\
\text { size } \\
\text { distribut }\end{array}$} & DMA & Grimm Vienna Type & TSI model 3081 \\
\hline & $\mathrm{CPC}$ & Grimm 5.403 & TSI model 3772 \\
\hline & $\begin{array}{l}\text { Size } \\
\text { range }\end{array}$ & $11-1000 \mathrm{~nm}$ & $9-800 \mathrm{~nm}$ \\
\hline \multirow{2}{*}{\multicolumn{2}{|c|}{$\begin{array}{l}\text { Number concentration } \\
\text { LDSA concentration }\end{array}$}} & Grimm 5.403 & TSI model 3007 \\
\hline & & NSAM TSI model 3550 & \\
\hline \multicolumn{2}{|c|}{ Comments } & $\begin{array}{l}\text { instruments connected to a } \\
2 \mathrm{~L} \text { homogenization } \\
\text { volume }^{(37)}\end{array}$ & $\begin{array}{l}\text { instruments placed in a } 23 \mathrm{~m}^{3} \text { chamber } \\
\text { with homogenously distributed aerosol } \\
\text { 64) }\end{array}$ \\
\hline
\end{tabular}




\begin{tabular}{|c|c|c|c|c|c|c|c|}
\hline \multicolumn{2}{|c|}{$\begin{array}{l}\frac{\tilde{g}}{0} \\
\frac{\pi}{2} \\
\frac{a}{0} \\
\dot{0}\end{array}$} & $\begin{array}{l}\frac{y}{\mathbb{E}} \\
\stackrel{E}{E}\end{array}$ & 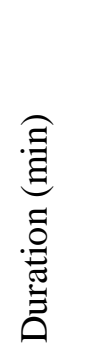 & 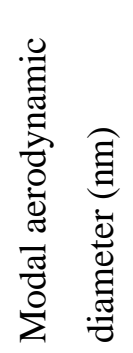 & 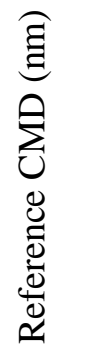 & 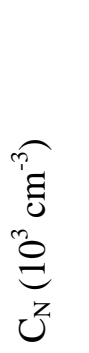 & 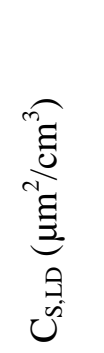 \\
\hline \multirow[t]{6}{*}{$\mathrm{A}$} & A1 & Big bag filling with pigmentary $\mathrm{TiO}_{2}$ & 1 & 40 & 57 & 17 & 31 \\
\hline & $\mathrm{A} 2$ & Closing big bag of nano- $\mathrm{TiO}_{2}$ & 0.5 & 74 & 104 & 25 & 118 \\
\hline & B & Discharging bags of powder of nano- $\mathrm{TiO}_{2}$ & 1 & 319 & 190 & 1.7 & 29 \\
\hline & $\mathrm{C}$ & Dry sandpapering of a reactor & 50 & 74 & 104 & 5.0 & 43 \\
\hline & $\mathrm{D}$ & Extrusion of polymer containing MWCNT & 30 & $<30$ & 42 & 154 & 619 \\
\hline & $\mathrm{E}$ & Fabrication of photocatalytic media & 5 & 123 & 173 & 355 & 2603 \\
\hline
\end{tabular}


Table 5. Comparison of Theoretical (SMPS-based) and Experimental (NSAM) LDSA Concentrations

\begin{tabular}{llll}
\hline Material & CsCl & DEHS & C \\
\hline Modal diameter $(\mathrm{nm})$ & 40 & 118 & 151 \\
GSD (-) & 1.84 & 1.75 & 1.57 \\
Number concentration $\mathrm{C}_{\mathrm{N}}\left(10^{3} \mathrm{~cm}^{-3}\right)$ & 9.7 & 14.2 & 132 \\
SMPS-based theoretical $\mathrm{C}_{\mathrm{S}, \mathrm{LD}}\left(\mu \mathrm{m}^{2} / \mathrm{cm}^{3}\right)$ & 25.5 & 92 & 1581 \\
Experimental $\mathrm{C}_{\mathrm{S}, \mathrm{LD}}\left(\mu \mathrm{m}^{2} / \mathrm{cm}^{3}\right)$ & 26 & 97 & 1606 \\
Bias $(\%)$ & +1.6 & +5.4 & +2.0 \\
\hline
\end{tabular}

